\title{
MORPHOLOGY OF THE FEMUR IN PROXIMAL FEMORAL FRACTURES
}

\author{
BARRY D. FERRIS, COLETTE KENNEDY, MANJIT BHAMRA, WILLIAM MUIRHEAD-ALLWOOD
}

From the Whittington Hospital, London

\begin{abstract}
We studied the morphology of the contralateral femur in 10 patients with subcapital fractures, 10 with trochanteric fractures and $\mathbf{1 0}$ with unilateral osteoarthritis. We found that the patients with trochanteric fractures had a significantly shorter femoral neck $(4.5 \pm 0.5 \mathrm{~cm})$ than patients with subcapital fractures or osteoarthritis $(5.4 \pm 0.4 \mathrm{~cm})$. It may be that this difference in femoral neck length is related to the site at which a proximal femoral fracture occurs.
\end{abstract}

The factors that determine whether a proximal femoral fracture is cervical or trochanteric are a matter of controversy. Lawton, Baker and Dickson (1983) suggested that the groups of patients were biologically different, and it is known that patients with trochanteric fractures tend to be older. Others believe that the site of fracture is determined by the mechanism of injury (Backman 1957; Hirsch and Frankel 1960). Kent et al. (1983) described the presence of relatively large crystals of hydroxyapatite localised to the subcapital fracture site. These hydroxyapatite crystals have recently been shown to be present at the trochanteric fracture site (Ferris et al. 1987), and it was considered that they were present before injury and may have contributed to local fragility, predisposing the bone to fracture.

Our present study was undertaken to determine whether there was any difference in the morphology of the femur between patients with subcapital and trochanteric fractures which may have influenced the level of the fracture.

\section{PATIENTS AND METHODS}

If a patient sustains a second contralateral proximal femoral fracture then there is an $83 \%$ chance that it will be of the same type as the first (Boston 1982). To investigate one possible reason for this finding we studied 10 patients with trochanteric fractures and 10 patients with subcapital fractures, comparing them with 10 patients who had unilateral osteoarthritis of the hip. In all 30 patients the normal, contralateral femur was measured.

Each hip was examined under an image intensifier, and the femur rotated until the minimum neck-shaft angle was seen. An anteroposterior radiograph was then taken, with a radio-opaque ruler at the level of the femur to assess magnification. From the radiographs we measured the neck-shaft angle (NS), the diameter of the femoral head, the length of the femur (L), the femoral neck and the offset of head from shaft (Fig. 1). The angle

Fig. 1

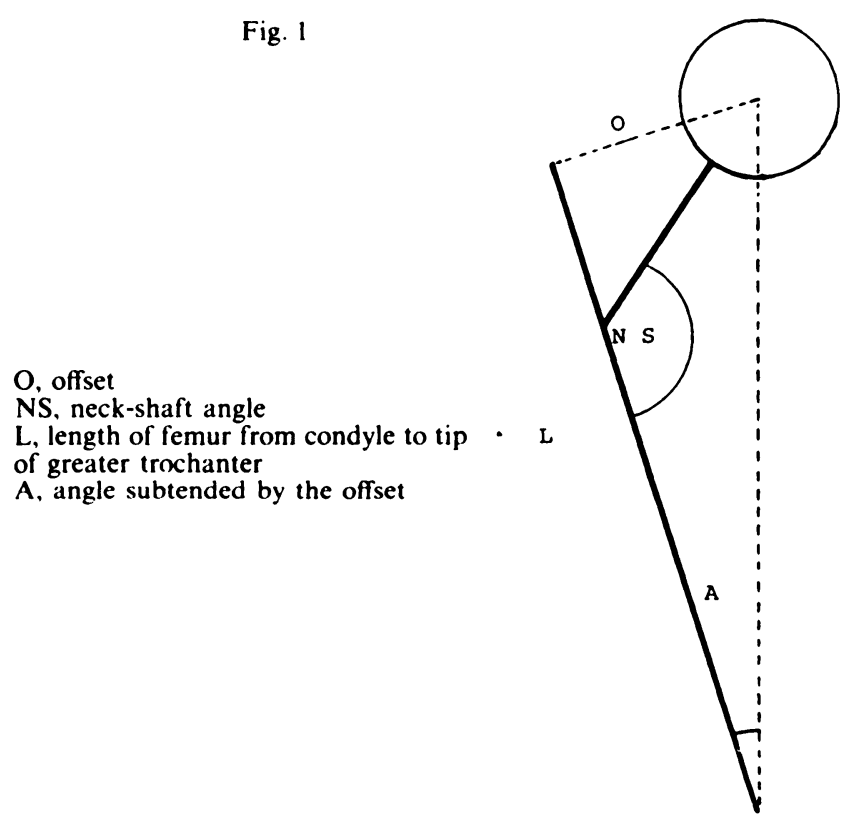

Diagram to show the measurements made on each contralateral femur. 
A was calculated (Table I). The length of the femoral neck was taken as the distance from its junction with the femoral head to the point from which the neck-shaft angle was measured. Statistical analysis was by Student's t-test.

\section{RESULTS}

The details of the patients and the results are shown in Table I. In one patient, rotation of the femur to determine the minimum neck-shaft angle was repeated five times to assess accuracy. The mean error was found to be $\pm 1.2^{\circ}$.

Table I shows that the mean age of the trochanteric fracture group was greater than that of the other groups, but the sex ratios were similar. Femoral length and femoral head diameter did not differ significantly between the three groups.

The main positive finding was that the femoral neck of patients with a trochanteric fracture was significantly shorter than that of those with either subcapital fracture $(p<0.001)$, or osteoarthritis $(p<0.001)$. The offset of the femoral head in the trochanteric fracture group was correspondingly smaller than in the subcapital fracture group $(0.05>p>0.01)$ but there was less difference with the osteoarthritic group. This apparent discrepancy in results can be explained by the larger neck-shaft angle found in the osteoarthritic group. Patients with subcapital fractures had a femoral morphology similar to that seen in osteoarthritic patients, but these had a larger neck-shaft angle. None of the other measurements were significantly different between the three groups.

\section{DISCUSSION}

Assuming femoral shape to be bilaterally symmetrical, our study provides no evidence of differing morphology between patients with a subcapital fracture and those with early contralateral osteoarthritis, while those with a trochanteric fracture have a significantly shorter femoral neck. The accurate measurement of neck-shaft angle is difficult because of femoral neck anteversion, which influences the radiographic projection; various methods of measurement have been described, including computed tomography (Murphy et al. 1987). We did not attempt to measure anteversion, but the method we used eliminated its effect and gave an error of only $\pm 1.2^{\circ}$.

Backman (1957) measured femoral morphology in patients with proximal femoral fractures, but did not look at possible differences between each fracture type. There have been studies of femoral neck angles in children (Ogata and Goldsond 1979) and in osteoarthritis (Reikerås et al. 1982), but a computer-assisted search failed to find any studies comparing subcapital with trochanteric fractures. Reikerås et al. (1982) found that the neck-shaft angle in osteoarthritis was $131^{\circ} \pm 7^{\circ}$ which was similar to our result $\left(131^{\circ} \pm 8^{\circ}\right)$, Backman (1957) found that the angle $A$ was $6^{\circ}$ and this also is similar to our findings $\left(6.3,6.5\right.$ and $\left.6.9^{\circ}\right)$. Thus some of our measurements agree with published data and suggest that our technique is valid.

Table I. Details of the three groups of 10 patients and the measurements of their contralateral femur (mean \pm s.d.)

\begin{tabular}{lccc}
\hline & \multicolumn{3}{c}{ Patient group } \\
\cline { 2 - 4 } & $\begin{array}{l}\text { Subcapital } \\
\text { fracture }\end{array}$ & $\begin{array}{l}\text { Trochanteric } \\
\text { fracture }\end{array}$ & Osteoarthritis \\
\hline $\begin{array}{l}\text { Age } \\
\text { (mean and range in years) }\end{array}$ & $69(54$ to 90$)$ & $84(71$ to 97$)$ & 69 (56 to 78) \\
Male : Female ratio & $2: 8$ & $1: 9$ & $1: 9$ \\
$\begin{array}{l}\text { Neck } \\
\text { (cm) }\end{array}$ & $5.4 \pm 0.4$ & $4.5 \pm 0.5$ & $5.6 \pm 0.5$ \\
$\begin{array}{l}\text { Shaft } \\
\text { (cm) }\end{array}$ & $35.3 \pm 2.7$ & $34.9 \pm 2.9$ & $35.9 \pm 2.4$ \\
$\begin{array}{l}\text { Head diameter } \\
\text { (cm) }\end{array}$ & $4.2 \pm 0.4$ & $4.0 \pm 0.3$ & $4.2 \pm 0.2$ \\
$\begin{array}{l}\text { Offset } \\
\text { (cm) }\end{array}$ & $4.3 \pm 0.4$ & $3.8 \pm 0.6$ & $4.1 \pm 0.6$ \\
$\begin{array}{l}\text { NS Angle } \\
\text { (degrees) }\end{array}$ & $125 \pm 7$ & $127 \pm 7$ & $131 \pm 8$ \\
$\begin{array}{l}\text { Angle A } \\
\text { (degrees) }\end{array}$ & $6.9 \pm 0.8$ & $6.3 \pm 1.2$ & $6.5 \pm 1.1$ \\
\hline
\end{tabular}

The observation by Boston (1982) that patients sustaining a second contralateral proximal femoral fracture had an $83 \%$ chance of having the same type of fracture suggests that there might be a general cause for the site of injury. Studies have been made of muscle pull and the mechanism of injury (Backman 1957; Hirsch and Frankel 1960), but none have been conclusive. We felt that the high chance of a second similar fracture on the contralateral side meant that differences in morphology should be large enough to be found in a relatively small number of patients. If any more patients were required to achieve statistical significance, then the importance of that parameter was questionable. An extension of this study should probably separate males from females, although we have no evidence that a particular fracture type is more common in either sex.

There is other evidence that the site at which a proximal femoral fracture occurs is independent of the mechanism of injury. Kent et al. (1983) found unusually large crystals of hydroxyapatite at subcapital fracture sites. Ferris et al. (1987) found similar crystals at trochanteric fracture sites, but such crystals were not found in the trochanteric region of patients with subcapital fractures. It seemed that the presence of these 
large crystals may have increased the fragility of the bone and predisposed it to fracture.

We found that patients who have had a trochanteric fracture have significantly shorter femoral necks than patients with either subcapital fractures or unilateral osteoarthritis. It seems possible that this could cause a difference in local loading and result in the deposition of hydroxyapatite crystals in the trochanteric region, and predisposition of this site for fracture. Other factors may well be present, but the difference in femoral morphology we have shown seems to be significantly related to the site of proximal femoral fractures.

We would like to thank Julie Poyatgi (Senior Radiographer) and Bryan Newman (Department of Statistics, University College, London) for their help.

No benefits in any form have been received or will be received from a commercial party related directly or indirectly to the subject of this article.

\section{REFERENCES}

Backman S. The proximal end of the femur: investigations with special reference to the etiology of femoral neck fractures; anatomical studies; roentgen projections; theoretical stress calculations; experimental production of fractures. Acta Radiol [Suppl](Stockh) $1957 ; 146: 1-166$

Boston DA. Bilateral fractures of the femoral neck. Injury $1982 ; 14: 207-10$.

Ferris BD, Dodds RA, Klenerman L, Bitensky L, Chayen J. Major components of bone in subcapital and trochanteric fractures: a comparative study. J Bone Joint Surg [Br] 1987;69-B: 234-7.

Hirsch C, Frankel VH. Analysis of forces producing fractures of the proximal end of the femur. J Bone Joint Surg [Br] $1960 ; 42-B: 633-40$.
Kent GN, Dodds RA, Klenerman L, Watts RWE, Bitensky L, Chayen J. Changes in crystal size and orientation of acidic glycosaminoglycans at the fracture site in fractured necks of femur. J Bone Joint Surg [Br] 1983;65-B:189-94.

Lawton JO, Baker MR, Dickson RA. Femoral neck fractures: two populations. Lancet 1983;ii:70-2.

Murphy SB, Simon SR, Kijewski PK, Wilkinson RH, Griscom NT. Femoral anteversion. J Bone Joint Surg [Am] 1987;69-A:1169-76.

Ogata K, Goldsond GM. A simple biplanar method of measuring femoral anteversion and neck-shaft angle. J Bone Joint Surg [Am] 1979;61-A :846-51.

Reikerås O, Heiseth A, Reigstad A, Fönstelien E. Femoral neck angles: a specimen study with special regard to bilateral differences. Acto Orthop Scand 1982:53:775-9. 